\title{
Management of Post-Traumatic Stress (PTSD) Dementia and Other Neuro-Degenerative Disease with Photo-Medicine: Clinical Experience and Case Studies
}

\author{
William Stephan ${ }^{*}$, Ronald Aung Din'2, Louis J. Banas', John Thomas', \\ Carolyn Kochert ${ }^{3}$, Randy J. Lamartiniere ${ }^{4}$, Carol Spooner ${ }^{5}$, Gerard Pesca ${ }^{5}$, \\ Dudley Chewning Eddy ${ }^{6}$ \\ ${ }^{1} 4080$ Delaware Ave, Tonawanda, New York, USA \\ ${ }^{2} 3501$ Cattlemen Drive, Sarasota, FL, USA \\ 33218 Daugherty Ave, Suite, Lafayette, IN, USA \\ ${ }^{4}$ Photo-Medicine 8676 Goodwood Boulevard, Baton Rouge, LA, USA \\ ${ }^{5}$ Laser Innovations LLC, 2451 East Baseline Road, Gilbert AZ, USA \\ ${ }^{6}$ LMFT, 820 Jordan St., Suite 570, Shreveport, LA, USA \\ Email: ^drwhs23@gmail.com
}

How to cite this paper: Stephan, W., Din, R.A., Banas, L.J., Thomas, J., Kochert, C., Lamartiniere, R.J., Spooner, C., Pesca, G. and Eddy, D.C. (2017) Management of PostTraumatic Stress (PTSD) Dementia and Other Neuro-Degenerative Disease with Photo-Medicine: Clinical Experience and Case Studies. Open Journal of Psychiatry, 7 , 386-394.

https://doi.org/10.4236/ojpsych.2017.74032

Received: August 25, 2017

Accepted: October 17, 2017

Published: October 20, 2017

Copyright ( $) 2017$ by authors and Scientific Research Publishing Inc. This work is licensed under the Creative Commons Attribution International License (CC BY 4.0).

http://creativecommons.org/licenses/by/4.0/ (c) (i) Open Access

\begin{abstract}
Objective: Photobiomodulation (also known as Low Level Laser. LLLT or Cold Laser; Photo Medicine (PM)) has been a vital adjunct therapy in our clinical practice over 5 years, observations of improvement in cognition and personality were noted in several patients. As a result, selected patients with Alzheimer's Disease, vascular dementia, post-traumatic brain injury and other neuro-degenerative diseases were treated at clinical practices in Buffalo, New York; Sarasota, Florida; Lafayette, Indiana; Phoenix, Az., and Baton Rouge, La. Over 60 patients were treated with an average of 4 times over an 8-day period all reported/exhibited improvement in their condition, except that two men who were in their seventies were in robust health but had no short-term memory and no improvement was observed. However, Theralase has developed a more efficacious system which will be more efficacious, due to increased power for ATP activation. Method: Over 150 patients with the above conditions were treated in various areas (depending on diagnosis) including the prefrontal cortex, temporal lobe, Hippocampus, and Circle of Willis for duration of two and one-half minutes every 48 hours for $5-6$ treatments. We utilized the Theralase multi-probe $(905 \mathrm{~nm} / 660 \mathrm{~nm})$ at 60 miliwatts. It utilizes 5 - $905 \mathrm{~nm}$ near infra-red diodes and 4 infra-red 660 laser diodes with a peak power of 50,000 milliwatts at peak and pulse duration of 200 nanoseconds [1].
\end{abstract}


The PTSD patients were evaluated utilizing the co-occurring disorders program screening and assessment form. Conclusion: Dementia patients exhibited varying degrees of improvement in cognitive function and personality, leading to improved quality of life and decreased caregiver burden. PTSD patients' improvement was objectively measured by formal neuropsychological testing utilizing the form. All PTSD patients scored no emotional problems after 3 - 5 treatments and all experienced overall sense of well-being. One experienced return of ability to smell he had not had for 5 years. Similar results were reported in a Japanese study where 15 patients were followed for a year. This non-invasive and non-systemic modality of therapy could play a key role in treating progressive neurodegenerative conditions, improving quality of life, and reducing health care costs.

\section{Keywords}

Photobiomodulation, Photo Medicine (PM), Neuroregeneration, Neuro-Degenerative Disease, Small Vessel Disease (SVD)

\section{Introduction}

Dr. Richard M. Restak published The Brain, The Last Frontier due to the fact that it is the one organ we still want to learn more about and how to treat [2]. It is well documented that many scientific discoveries are the result of a serendipitous event (Isaac Newton). We believe that in 2009, we were the witnesses for such a discovery. The opportunity to use this new technology, Low Level Laser Therapy (LLLT) now referred often referred to as Photo-Medicine (PM) was in Dr. Stephan's private practice. Extensive research is now being done in the United States. One recent publication by Dr. Theodore Henderson utilizes a laser like the one used in our practice. His article published in May 2016 "Multiwatt near infrared light therapy as neurogeneration for TBI" [3] further reinforces the need for more formal studies in this field. One of the first formal studies done in 2013 concludes "...Shown to regulate neuronal function in cell cultures, animal models and clinical conditions. Light that intersects with the absorption spectrum of cytochrome oxidase was applied to the forehead... it was generally reported more positive effects then overall affect states then negative, overall affect improved significantly... Cytochrome oxidase is an ideal target for cognitive enhancement, as its expression reflects the changes metabolic capacity underlying higher order brain functions [4].” Dr. Stephan, a well-respected, primary care physician, places heavy emphasis on preventive and alternative medicine. He has been using PM for over 11 years and as a primary care physician sees all types of injury. Although a great deal of success was experienced, the most remarkable improvements were for PTSD, migraine, concussion, and dementia. Patients who had suffered a concussion or migraine had significant and sometimes total healing with just a few treatments. We knew this was remarkable 
but we assumed we were only treating superficially, not knowing the skull is translucent. Similar results were duplicated by a very progressive Neurologist in Sarasota, Florida, Ronald Aug-Din M.D. co-author of this paper. Michael Hamblin has been doing extensive work in this area and his recent publication Shining light on the head: Photo biomodulation for brain disorders highlights the following observations: "NIR light can penetrate the head and reach the brain; NIR is absorbed by cytochrome oxidase in mitochondria; Increased blood flow, energy, neuroprotection, less inflammation, brain repair; Can treat traumatic stroke (stoke TBI), neurodegenerative and psychiatric disease [5]."

In a previous case study publication, a young man was hit with a lead pipe and had intractable migraines for two years; he was healed with just 4 treatments [6]. Because of this observation, the issue of dementia and PTSD were addressed in the clinic. All patients were treated utilizing the Theralase TLC 900 series Low Level Laser.

\section{Case Studies}

\section{PTSD evaluation}

The Co Occurring Disorders Program Screening Assessment questionnaire is universally accepted as a valid assessment of an individual's degree of emotional distress due to a traumatic event(s). A score of 35 indicates a mild case and a score of 55 or above indicates a severe disorder. The individuals here all presented here had scores over 55 and unless indicated; scores are presented before the first and after a fourth session. Over 50 individuals were treated over a one-year period at 5 different locations which included: Phoenix Az.; Buffalo, NY; Lafayette Ind., Bossier City, La.; and Sarasota, Fla. virtually all patients exhibited and proclaimed remarkable improvement in their emotional stability and quality of life which is indicated in their scores. The following cases are a sample of notable cases by providers in the cities indicated.

1) A 32-year-old independent business man in Buffalo, New York, witnessed the murder of his mother when he was 9 years old and the murderer was never convicted. He claimed the over the last 2 - 3 years he fired over 30 employees due to his inability to cope with stressful situations. He stated he no longer experienced the problem and his life is significantly better. (Questionnaire not utilized).

2) A 69-year-old Vietnam Vet after 50 years of emotional problems had just coincidently contacted the VA the week before becoming aware of the treatments. He holds executive management position but knew he had issues. After completing a series of 4 treatments over an eight-day period he felt significant relief. He did not follow up with the VA. Scores: 47/27.

3) A 54-year-old woman from Rochester, NY was on SSI due to a diagnosis for PTSD as the result of an abusive spouse. After 6 treatments, her score indicated remarkable improvement in her emotional well-being. She was given a 3 more "maintenance" treatments over a 4-month period and her testimonial video 
can be viewed at www.paintherapyusa.com. Scores 62/25.

4) A 75-year-old woman from Sarasota, Fla. was forced into prostitution at the age of 19 in New York City. After the second treatment, she had remembered she had an abortion at the age of 21 . This event was "blanked out" in her memory and she cried in the office on subsequent occasions stating she had "killed" a baby something deeply against her convictions. After the $5^{\text {th }}$ treatment among other "improvements" she now could enjoy dining, driving her car by herself, and her handwriting was now legible. Questionnaire not utilized.

5) A 45-year-old man in Phoenix, Az endured multiple beatings as a child was accidently electrocuted at work and thrown 30 feet to the ground; doctors felt the fall restarted his heart. Because of the accident, he underwent stress management, tempers management and had severe muscular skeletal pain for several months. The PTSD questionnaire was administered and he scored very high. After 5 treatments over a 10-day period he no longer suffered from PTSD, was virtually pain free, was relaxed, no longer short tempered and was no longer prone to sudden outbursts of anger. Scores 67/32.

6) A 40-year old Navy Seal (ret) was asked to by his wife (a physician) to seek this therapy she had heard about. He insisted he did not have a problem but acquiesced to her request. After the second session, he remarked about how much better he felt and his wife was requesting all information available. Score 55/25 (only three sessions needed).

\section{Vascular Dementia}

1) An 88-year-old woman, wheel chair bound started having simple memory problems (dementia) eight years previously. She recently was forced to move in with her son due to aberrant behavior in the skilled nursing facility. She would have violent outbursts towards others when confused or if more than two or three people were in her presence. Her energy level was very low. Six treatments were administered over a twelve-day period. Her son reported that she was much more relaxed and outbursts were non-existent. In addition, in the evening she maintained a much higher energy level and was much more alert. The son was very pleased with the change in her entire demeanor and after a 5-week period notices a small decline in her condition. Therefore, a monthly a monthly treatment is being administered for maintenance purposes.

2) A 38-year-old female, under the care of this primary care physician for 3 months had a history of stroke and possible TBI due to spousal abuse. She sought treatment for severe migraines of various degrees 3 - 4 times per week over a 5-year period. Her previous primary care physician had her on a very high dosage of Oxycotin. After the first treatment, her headache pain was almost eliminated, however due to cut back on her medication the migraines continued. A course of 8 treatments (some on an emergency basis) were administered over a 14-day period and she received significant relief every time. However, after the seventh treatment the mother reported her daughter began speaking in full sentences and her memory had returned. In addition, she no longer needed to walk with a cane. The client was followed up intermittently over a two-year period 
and no regression was apparent.

\section{Dementia: Early stage}

Case 1. A 77-year-old was first diagnosed with dementia 12 years previously and although taking several memory medications still had to be admitted to a memory home. His memory was severe and he recognized his daughter but did not know her name even though she visited him 3 - 4 times per week. After the fourth treatment, the daughter called and reported to me that his brother stopped by to see him for the first time in months and he not only called him by name but they cried and had a conversation. He was treated the next day and upon our arrival while sitting in the dining room he recognized his daughter waved to her and called out to her by name. This was a startling improvement which he had not demonstrated for years. A fifth treatment was administered at that time however the daughter then left for ten a day vacation. Upon her return, he had reverted to his previous condition and after several treatments the condition could not be duplicated.

Case 2. A 67-year-old postal worker still working part time was getting concerned about memory lapse and sense of smell loss. Both his parents died of Alzheimer's in their 80's. A series of 6 treatments were administered as a preventive measure. He reported that he has regained sense of smell and in addition, he reported a side effect $\{$ ? $\}$ of 3 small, fleeting headaches something which he never experiences. We conjecture this may be the result plaque or tau protein moving through his system? Two years later he shows no sign of any degeneration and still has his sense of smell.

Case 3. A 61-year-old retired housewife had a very rapid decline over a 9-month period. The daughter (caretaker) had planned to move to another city where she would have more family. The daughter agreed to allow a least a series of six treatments. After the second treatment, the receptionist was shocked that she asked to sign her credit card receipt.

After the sixth treatment, the daughter reported that she now dresses herself without help and if she makes a mistake the daughter points it out and she corrects the problem herself. In addition, she can now get into the car and fasten her seat belt without any assistance. Also, she had a problem eating a sandwich whereas she would pick up the top slice of bread and the daughter would need to correct her, which was no longer a problem.

\section{Case 4. Advanced dementia case (Ongoing case)}

An 82 -year-old male with a 10 years' history is being treated 3 times a week continuously since November 2014. Subject is a retired medical researcher and wife a retired school teacher. Careful documentation is being kept by his wife. At the outset within a two-week period, the client slept through the night giving his caretaker wife and family much relief from anxiety and sleep deprivation; before this time, he would wander around the house at all hours of the night. His echoing also was minimized in the first few months and conversation was improved. A memory test is administered twice a week and he showed stabilization. However, after the fourth month echoing became more pronounced and he 
no longer could associate his wife as a loved one. He could not recognize his son he had not seen in two years who came to visit however his son who visits 2-3 times a year is recognized. Physical and OT therapists state he is doing extremely well at this stage, however much credit must be given to the wife for the many activities she engages him in including puzzles and the math games.

\section{Discussion}

There are more than 5 million Americans currently living with Alzheimer's disease and per the American Alzheimer's Association every 67 seconds someone in the United States develops the disease. Estimates of costs to American society are $\$ 214$ billion including Medicare and Medicaid. These costs are staggering yet if we do not find a cure the cost in today's costs would be $\$ 1.2$ trillion by 2050 . Extensive research is being conducted worldwide and recent studies that Alzheimer's (AD) could be more closely related to Small Vessel Disease (SVD) than previously thought. As recent as May of this year JAMA Network Journals reported "Cerebral SVD and AD disease pathology appear to be associated, new research indicates. 'Our study supports the hypothesis that the pathways of SVD and $\mathrm{AD}$ are inter-connected. SVD could provoke amyloid pathology while $\mathrm{AD}$-associated cerebral amyloid pathology may lead to auxiliary vascular damage' researchers conclude [7]." Dr. Sandra Black a prominent Alzheimer researcher in Toronto Canada during a recent radio talk show theorized that exercise is one area for prevention that could be a solution in mitigating the problem. The inference here is that increased blood during cardio vascular exercise might mitigate the buildup of plaque and protein. However, recent theory may conclude that good blood flow keeps neural tissue from degenerating. Specialist's concede that Vascular

Dementia is directly related to SVD which by estimates accounts for $10 \%$ $20 \%$ of all dementia cases. Alzheimer's is a more insidious disease with the knowledge that the vascular system is hampered by the buildup of amyloid plaque and tau protein. Because of this build up much attention is being given to prevention as well as cure. The most recent, first controlled human study of its kind done at the Goethe Institute in Germany further concludes that aerobic exercise renders the brain more efficient, plastic and adaptive, which leads to improved memory and executive function. In brief, mechanisms comprise positive functional changes in hemodynamic activity, synaptic plasticity, neurogenesis, and neural cell proliferation with newly formed neurons being integrated functionally into neural networks [8]. Lew Lim Ph.D. of Toronto, Canada treated five patients with mild to moderately severe cognitive impairment over a four-week period utilizing a transcranial and intranasal laser device. He concludes "this therapy may be safely used with mild and moderately severe dementia. and Alzheimer's. Results showed significant improvement in cognition, functional abilities for daily living and improved quality of life. Laser was very well tolerated exhibiting no adverse effects [9].

A study by Naser et al. looked at the use of LLLT for the treatment of Traumatic 
Brain Injury (TBI) stroke and neurodegenerative disease. Their results were very promising. Nightly treatments over a long period improved cognitive abilities. In addition, they showed that the use of LLLT increased ATP production, caused vasodilation and improved perfusion. They presented two cases where cognitive ability was regenerated [10]. Two mouse studies both concluded that LLLT showed promise: Farfara D., et al., recently reported: "LLLT stimulated mesenchymal stem cells increased their ability to maturate towards monocyte lineage as to increase phagocytosis activity towards soluble amyloid beta (A b) Furthermore, weekly LLLT administered to the bone marrow of Alzheimer mice for two months starting at 4 months of age (progressive stage of AD) improved cognitive capacity and spatial learning as compared to the sham group. Histology revealed a significant reduction in A $b$ burden [11]."

Another study by Sivaraman Purushothuman et al. concluded: "our results in two transgenic mouse models with existing $\mathrm{AD}$ related pathology suggest that (LLLT) can reduce characteristic pathology, oxidative stress and mitochondrial dysfunction in susceptible regions of the brain. These results when taken together with those other models of neurodegeneration strengthen the notion that LLLT is a viable neuro-protective treatment for a range of neruodegenerative conditions. We believe this growing body of work provides the impetus to begin trialing LLLT as a broad base therapy for $\mathrm{AD}$ and other neurodegenerations [12].

Promising work was published in Japan by Kazuyoshi Zenba. Zenba utilizing similar technology in 1993 treated senile dementia with very good results. They followed 15 patients with Alzheimer's over a one-year period, treating them 2 - 3 times a week for that period. He reported "Among evaluation items, cooperativeness and the lack of composure were observed as useful as an effect, the effect appeared half a year after and continued for one year and later. It was suggested that there was an improvement of orientation disturbance, normalization of clothing and dress... it was also reported the coldness of hands and legs of patients vanished and joints and muscular stiffness were also mitigated." He continues: "Also in excretion care, it became very easy to carry out the care of the patients." Also, "...the following effects were confirmed, namely the advance of condition of Alzheimer's diseases has been blocked and the expression of patients changed to smiling from disinterestedness, cooperativeness came out and understanding came to be shown to a partner [13].”

\section{Conclusion}

These case studies presented indicate the veracity of PM as being a minimal invasive, painless modality that may mitigate and in many cases reverse neurodegeneration in the present population. We hypothesize currently that PM is unique in its ability to penetrate to the brain tissue providing rapid vasodilation (increase in blood flow) and reduced oxidative stress enabling the processes to formulate. Moriyama compares standard, therapeutic wavelengths and concludes that the $905 \mathrm{~nm}$ is vastly superior to produce Nitric Oxide responsible 
for vasodilation [14].

More extensive clinical studies are being planned to verify the efficacy of the treatment, if the treatments are to be used as an acceptable, medical, preventive measure with neurodegenerative disease. PET scans of patients who have a family history of dementia or Alzheimer's could be identified as having SMD, therefore qualifying them as the proper candidates for a study.

Controlled studies for dementia are being planned by Lee in Boston and San Francisco this year. A controlled study for PTSD is being planned in Buffalo, NY. Currently 8 clinics nationally are now providing this therapy in the United States.

\section{References}

[1] Theralase Inc. Toronto, Canada.

[2] Restak, R.M. (1980) The Brain, The Last Frontier. Mass Market Paperbooks, January 1.

[3] Henderson, T.A. (2016) Milliwatt Near-Infrared Light Therapy as Neurogeneration for TBI. Neural Regan Res, 11, 563-565.

[4] Rojas, J.C. and Gonzalez-Lima, F. (2013) Neurological and Psychological Applications of Transcranial Lasers and LEDS. Biochemical Pharmacology, 86, 447-457. https://doi.org/10.1016/j.bcp.2013.06.012

[5] Hamlin, M.R. (2016) Shining Light on the Head: Photo Biomodulation for Brain Disorders. Science Direct BBA Clinical, 6, 113-124.

[6] Stephan, W., Banas, L.J., Bennett, M. and Tunceroglu, H. (2012) Efficacy of Super-Pulsed $905 \mathrm{~nm}$ Low Level Laser Therapy (LLLT) in the Management of Traumatic Brain Injury (TBI): A Case Study. World Journal of Neuroscience, 2, 231-233. https://doi.org/10.4236/wjns.2012.24035

[7] JAMA Network Journals (2014) Association between Small Vessel Disease, Alzheimer Pathology Studied. JAMA Network Journals, May 12.

[8] Lienerth, Pilatus, U., Schwarz, S., Tesky, V.A., Vogt, L., Banzer, W. and Pantel, J. (2017) Effects of Aerobic Exercise on Brain Metabolism and Grey Matter Volume in Older Adults: Results of the Randomized Controlled SMART Trial. Translational Psychiatry (2017)7, published online 18 July 2017.

[9] Anita, E., Saltmarche, R.N., Naeser, M.A., Ho, K.F., Hamblin, M. and Lim, L. (2017) Significant Improvement in Cognition in Mild to Moderately Severe Dementia Cases, Treated with Transcranial Plus Intranasal Photobiomodulation: Case Series Report. Laser Surgery, 2017. online.liebertpub.com

[10] Naser, M.A. and Hamblin, M.R. (2011) Potential for Transcranial Laser or LED Therapy to Treat Stroke, Traumatic Brain Injury and Neurodegenerative Disease. Photomed Lasiurus, 29, 443-448 www.ncbi.nlm.nih.gov/pubmed/21172691

[11] Farfara, D., Tuby, H., Trudler, D., Doron-Mandel, E., Maltz, L., Vassar, R.J., Frenkel, D. and Oron, U. (2014) LLLT Ameliorates Disease Progression in a Mouse Model of Alzheimer's Disease. J mol Neuroscience July 4; George S. Wise Faculty of Life Sciences, Tel Aviv University, Israel. http://www.healinglightseminars.com/laser-research-library/alzheimer-disease

[12] Purushothuman, S., Johnstone, D.M., Nansdasena, C., Mitofanis, J. and Stone, J. (2014) Photbiomodulation with Near Infra-Red Light Mitigates Alzheimer's Disease-Related Pathology in Cerebral Cortex-Evidence from Two Transgenic Mouse 
Models. Alzheimer's Research \& Therapy, 6, 2.

www.ncbi.nlm.nih.gov/pmc/articles/pmC3978916

[13] Zenba, K. and Inoue, M. (n.d.) The Efficacy of $904 \mathrm{~nm}$ Laser Therapy for Alzheimer's Disease.

[14] Moriyama, Y., Nguyen, J., Akens, M., Moriyama, E.H. and Lilge, L. (2009) In Vivo Effects of Low Level Laser Therapy on Inducible Nitric Oxide Synthase. Lasers in Surgery and Medicine, 41, 227-231. www.ncbi.nlm.nih.gov/pubmed/19291752 https://doi.org/10.1002/1sm.20745 